\title{
The Challenge of Indoor Air Quality Management: A Case Study in the Hospitality Industry at the Time of the Pandemic
}

\author{
Sara Zanni ${ }^{1, * \mathbb{C}}$, Gabriella Motta ${ }^{2}$, Matteo Mura ${ }^{1}$, Mariolina Longo ${ }^{1}$ and Davide Caiulo ${ }^{2}$ \\ 1 Department of Management, University of Bologna, 28, Via Terracini, 40131 Bologna, Italy; \\ matteo.mura@unibo.it (M.M.); mariolina.longo@unibo.it (M.L.) \\ 2 Planetwatch Sas, 50 rue Gustave Eiffel, 01630 Saint-Genis-Pouilly, France; \\ gabriella.motta@planetwatch.io (G.M.); davide.caiulo@planetwatch.io (D.C.) \\ * Correspondence: sara.zanni7@unibo.it
}

Citation: Zanni, S.; Motta, G.; Mura, M.; Longo, M.; Caiulo, D. The Challenge of Indoor Air Quality Management: A Case Study in the Hospitality Industry at the Time of the Pandemic. Atmosphere 2021, 12, 880. https://doi.org/10.3390/ atmos12070880

Academic Editor: Shai Kendler

Received: 28 May 2021

Accepted: 4 July 2021

Published: 7 July 2021

Publisher's Note: MDPI stays neutral with regard to jurisdictional claims in published maps and institutional affiliations.

Copyright: (c) 2021 by the authors. Licensee MDPI, Basel, Switzerland. This article is an open access article distributed under the terms and conditions of the Creative Commons Attribution (CC BY) license (https:/ / creativecommons.org/licenses/by/ $4.0 /)$.

\begin{abstract}
Air quality management represents a reason for concern in indoor environments, especially now that the COVID-19 pandemic has shown how microbial aerosols pose a threat to human health, requiring proper monitoring. This is particularly true in public and working environments, where the turnover of occupants is high. The hospitality sector, in particular, has been severely affected by limitations related to emergency containment, and it needs to redefine its operations in the perspective of a "new normal" in the post-COVID-19 era. Considering the necessity to provide consistent information about indoor air quality, promote adequate management and increase safety, we developed a case study in cooperation with a major hotel in Turin. A sensing network has been implemented based on corporate-grade monitoring devices, compliant with the RESET standards, recently proposed and applied here to the hospitality sector for the first time. The network is able to detect the concentration of gaseous contaminants and fine particulate matter in semi-continuous mode. The study involved areas of the hotel with different purposes, such as guestrooms, hall, kitchen, restaurant and fitness center. Several valuable insights emerged in support of air quality management and pathways for future research can be outlined, based on the innovative dataset developed.
\end{abstract}

Keywords: air quality management; hospitality; continuous air monitoring

\section{Introduction}

Air quality is gaining increasing attention, both among academics and practitioners, due to the rising evidence of its impacts on human health. The World Health Organization (WHO, Geneva, Switzerland) [1] estimates that about seven million premature deaths occur worldwide due to long-term exposure to poor air quality every year, related both to outdoor and indoor air quality. The focus of regulations about air quality has historically been on the protection of human health against the negative effects of exposure to airborne pollutants, through two main orientations. On the one hand, in the outdoor environment, with the setting of a concentrations limit for airborne pollutants of concern typical of urban areas (e.g., particulate matter, nitrogen compounds and ozone) [2]. On the other hand, in working environments, setting threshold limit values (TLV) for target substances deriving from the specific activities carried out [3]. In the first case, international frameworks have been developed to align national approaches to the management of pollution sources in different contexts, such as industrial (for the EU context, 2010/75/EU Directive of the European Parliament and the Council on industrial emissions; for the U.S., Clean Air Act-United States Code as Title 42, Chapter 85-and National Emission Standards for Hazardous Air Pollutants (NESHAP); for China, the 13th Five-Year (2016-2020) Plan for Economic and Social Development) or urban (for the EU, 2008/50/EC Directive on Ambient Air Quality and Cleaner Air for Europe and 2004/107/EC Directive on heavy metals and polycyclic aromatic hydrocarbons; for the U.S., amendments to Clean Air Act, 1990; for China, National Ambient Air Quality Standard (GB3095-2012)). In the second case, 
standards have been set at the international level to limit the exposure of professionals to instant or long-term threats (for the EU, Directive 2009/161/EU-indicative occupational exposure limit values; for the U.S., specific regulations are developed at State level, such as California, with the California Labor Code $\$ \$ 6300$ et seq., and New Jersey, with Indoor Air Quality standard, N.J.A.C. 12:100-13 (2007); for China, Occupational Diseases Prevention and Control Act of 2002).

Nevertheless, little is currently said about indoor air quality in civil environments, even though we spend about $90 \%$ of our time indoors [4], among households, working places, leisure, shopping and various services. The level of air pollution has been proven to be remarkably higher in indoor environments compared to the outdoors, even in the presence of everyday-life activities [5-7], to which the release of specific contaminants is related, or due to the location of the buildings in generally polluted areas, as demonstrated by Lucialli et al. [8]. Among others, particulate matter (PM) and volatile compounds (VOCs) represent relevant groups of contaminants, as they both include a variety of substances and may, therefore, pose threats to human health, especially in the long term. PM is, in fact, a mix of different substances: solid particles of a wide range of characteristic dimensions, particularly fine and ultrafine, in the case of indoor environments, liquid droplets [9] and secondary organic aerosol (SOA) [10]. The World Health Organization has listed PM among carcinogens [11], and the risk increases with the decreasing size of particles involved, as they acquire the ability to travel along the deep airways and reach more sensible areas, such as pulmonary alveolus. VOCs are a broad set of airborne contaminants which are typically related to photochemical smog and, consequently, tropospheric and ground-level ozone formation, in the outdoor environment. In indoor environments, they represent an element of concern, as several VOCs are listed among carcinogenic compounds (e.g., formaldehyde, methylene chloride, acetaldehyde, perchloroethylene, etc.) and consequently pose a threat to human health. In addition to this, they are involved in chemical reactions, able to generate sub-micron sized particles and by-products that may be associated with negative health effects in sensitive populations. Anthropic activity is widely regarded as the main source of air pollution in indoor environments. PM can result from physical activity in the room at different levels of engagement, from the simple walking [12] to more complex activities [13], but also cooking [6,7] and cleaning, especially when detergents [5] and vacuuming [14] are involved. VOCs may be generated not only by activities using chemicals (such as painting, dry cleaning, disinfectants, etc.), but also released on surfaces (i.e., furniture, coatings, textiles, etc.). As in the outdoors, VOCs may react with the indoor ozone, deriving, for example, from office equipment such as printers, or from air purifiers such as ionizers, or from the outside, even in low concentrations (i.e., below public health standards).

The onset of the COVID-19 pandemic has drawn additional attention to air quality, by considering its direct impacts on human health on a very short timescale. Air quality, in fact, has been proven to affect epidemiological parameters of the pandemic, such as mortality rate and spreading potential, in terms of risk determinants, i.e., vulnerability and exposure. First, in terms of vulnerability, the outdoor air quality has been proven to carry a significant impact, as recent studies have shown evidence for a link between long-term exposure to air pollution and an increase in mortality from SARS-CoV-2 infection [15], as testified by the exceptional mortality rates in Northern Italy, where air quality is particularly poor [16]. Second, in terms of exposure, studies developed during the pandemic have pointed out a potential risk of infection via aerosol, i.e., a suspension of solid particles or liquid droplets in the air [17-20]. The airborne pathway is physically able to spread viruses over a distance of about $2 \mathrm{~m}$ from the source, i.e., an infected person, as aerosols and particles can act as carriers for the microbial components, but only in recent years has it been proven as an effective transmission route for different diseases, from SARS-CoV-2 to avian influenza and measles [19,21-24]. Indoor environments require, in this sense, adequate attention, as they are typically affected by limited ventilation and, possibly, crowding, increasing the probability of exposure to microbes. For these reasons, management protocols have been 
outlined during the last months to increase the safety of indoor areas, and activities with higher risk parameters have been subjects to restriction measures, limiting the use of the premises or the number of accesses (such as in restaurants, fitness clubs, nightclubs, offices and working places).

For the hospitality industry, the COVID-19 pandemic constitutes an unprecedented crisis, setting the clock back by about 30 years. The tourism industry used to contribute, on average in OECD countries, 4.4\% of gross domestic product (GDP), $6.9 \%$ of employment, $21.5 \%$ of service exports [25] and $6.5 \%$ of global exports [26]. Considering international tourism, the sector is estimated to have declined between 70\% [27] and 80\% [25] across the world during 2020. OECD foresees a reasonable return to pre-pandemic levels not before 2023, due to a combination of limited travelers' confidence and measures in place. Travel restrictions are expected to remain in place for the near future, at different levels of severity and with discontinuous patterns along time and across countries, adjusted based on the progress of the pandemic. Therefore, a "new normal" must be outlined for the hospitality sector, to boost its resilience towards the post-COVID-19 era. Management modes, routines and protocols able to deal with the transient period, together with technological innovation aimed at improving the safety conditions of re-opening, can guarantee a safe utilization of indoor environments for both staff and guests and, consequently, rebuild their confidence in the short term [28]. Both technical and management controls are crucial actions to minimize the exposure of people to the virus, possibly travelling in the indoor air through the mechanisms mentioned above, as suggested by Kumar and Morawksa [17] and Morawska et al. [29]. In particular, once enhanced sanitization protocols have been implemented for the premises, IAQ monitoring appears strategic in the definition of safety conditions for the use of indoor environments, to verify the exposure to poor air quality on a regular basis. For this purpose, the application of dense networks of low-cost sensors would provide instruments for the long-term management of the issue. This could also support the design of additional solutions, both in terms of technological equipment (e.g., air purification) or management protocols aimed at reducing the risks, but also at enhancing customers' experience [30], in the post-pandemic era. Environmental quality in general, and IAQ in particular, has been perceived as an element of concern even before the present crisis, in the hospitality sector [31], as well in sectors related to it (e.g., airport facilities management [32]), as IAQ is recognized as an element to enhance the health and comfort of travelers and, therefore, a selling point with high growing potential. Previous studies in the field focused mainly on PM monitoring $[6,13,31,33,34]$, and for limited periods of time (e.g., hours, in the case proposed by Asadi et al. [33], or days [34]).

Based on these premises, we developed a longitudinal case study during the COVID19 crisis in collaboration with a major Italian hotel, with the overarching aim of providing support to the recovery of the hospitality activities, based on insights gathered by IAQ. Specifically, our study has the following aims: (i) developing a longitudinal data collection for IAQ in semi-continuous mode over a 16-week timespan, while previous studies in the field of IAQ in the hospitality sector focused on limited periods of time, (ii) collecting IAQ data in different environments within a hospitality premise, overcoming the limitation to specific areas (e.g., guestrooms or restaurants), and (iii) integrating data about different airborne contaminants of concern in indoor environments, to better capture the overall IAQ trends, affected by sources of contamination of a different nature in different environments.

This was accomplished by implementing an integrated IAQ continuous monitoring system of different parameters, i.e., PM, VOCs and $\mathrm{CO}_{2}$, aimed at collecting data to build a robust dataset for the characterization of IAQ in the hospitality industry. Different environments have been included in the present study and the monitoring period covered 16 weeks. 


\section{Materials and Methods}

\subsection{Experimental Design}

The project was developed through a partnership with a major hotel of Turin, i.e. DoubleTree by Hilton Turin Lingotto, with the aim of supporting the management of air quality at the time of pandemic. Considering the unavailability of technologies able to monitor microbial contamination in real time, a set of parameters has been defined for the characterization of IAQ, able to describe the crowding conditions of the indoor environments and the possible sources of pollution. In particular, we identified PM, VOCs and $\mathrm{CO}_{2}$ as key contaminants of concern. Environments with different purposes have been monitored, in order to characterize the IAQ of the whole premise over a long period of time.

The monitoring activity was carried out in an online semi-continuous mode, along 16 weeks, across winter and spring of 2021. Data were analyzed to describe the contamination developed throughout the whole period of the study, in the different environments tested.

\subsection{Site Details}

The building was designed by Renzo Piano and it is located in the historic former FIAT factory, next to the Lingotto Congress Center and the underground station, in the city of Turin (Northern Italy). This hotel retains a distinguishing architecture, with large windows and high ceilings, providing natural light, and the former FIAT test track on the roof. The hotel has 144 rooms developed over 4 floors and typically hosts guest all throughout the year, visiting the city not only for business purposes but also for tourism. The building is equipped with a centralized air treatment and ventilation system, treating all the different environments uniformly.

The monitoring network has been distributed over different kinds of environments and, in particular, the overall ratio was to cover spaces regularly occupied, namely by at least 1 person for not less than $1 \mathrm{~h}$ a day, and the rooms have been chosen in sufficient numbers to represent each floor. The following table (Table 1) reports details of the monitored environments, in terms of approximated size and the number of monitoring devices installed.

Table 1. Detailed presentation of the environments monitored, in terms of number of areas, approximate size and number of devices installed.

\begin{tabular}{cccc}
\hline $\begin{array}{c}\text { Monitored } \\
\text { Environment }\end{array}$ & Number of Areas & Approx. Size (m) & $\begin{array}{c}\text { Number of } \\
\text { Monitoring Devices }\end{array}$ \\
\hline Hall & 1 & 140 & 1 \\
Rooms & 24 & 29 each & 24 \\
Kitchen & 1 & 96 & 1 \\
Restaurant & 1 & 370 & 1 \\
Fitness Center & 1 & 48 & 1 \\
\hline
\end{tabular}

The following figures (Figures 1-5) report the outline of the monitored environments (in light blue) and the location of each monitoring device (in green). The placement of the devices has been defined based on a compromise between the ideal location, i.e., the most representative of the average IAQ within the room, and the availability of the power supply. Each device has been installed at least $1.5 \mathrm{~m}$ from the floor, on walls free from direct sources of pollution, e.g., HVAC units, printers, cooking or cleaning stations, etc. 


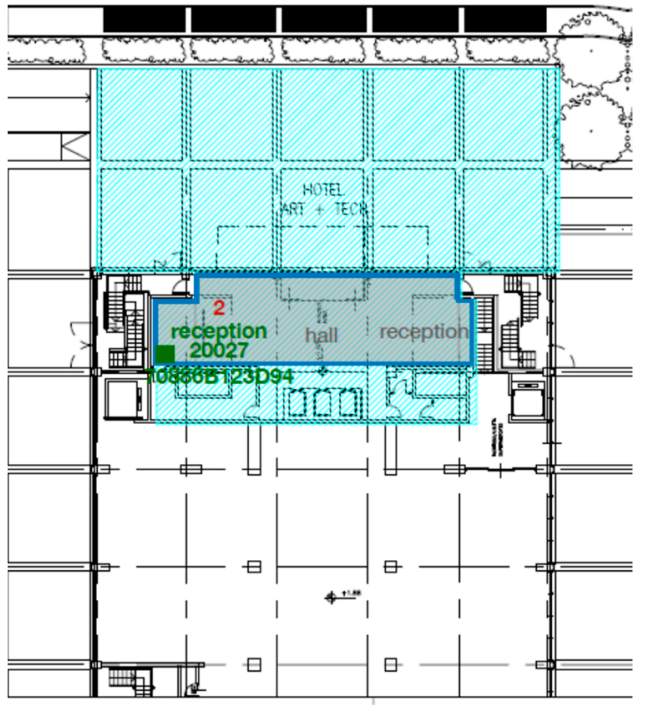

Figure 1. Floorplan of the hall area, with indication about the placing of the monitoring platform.

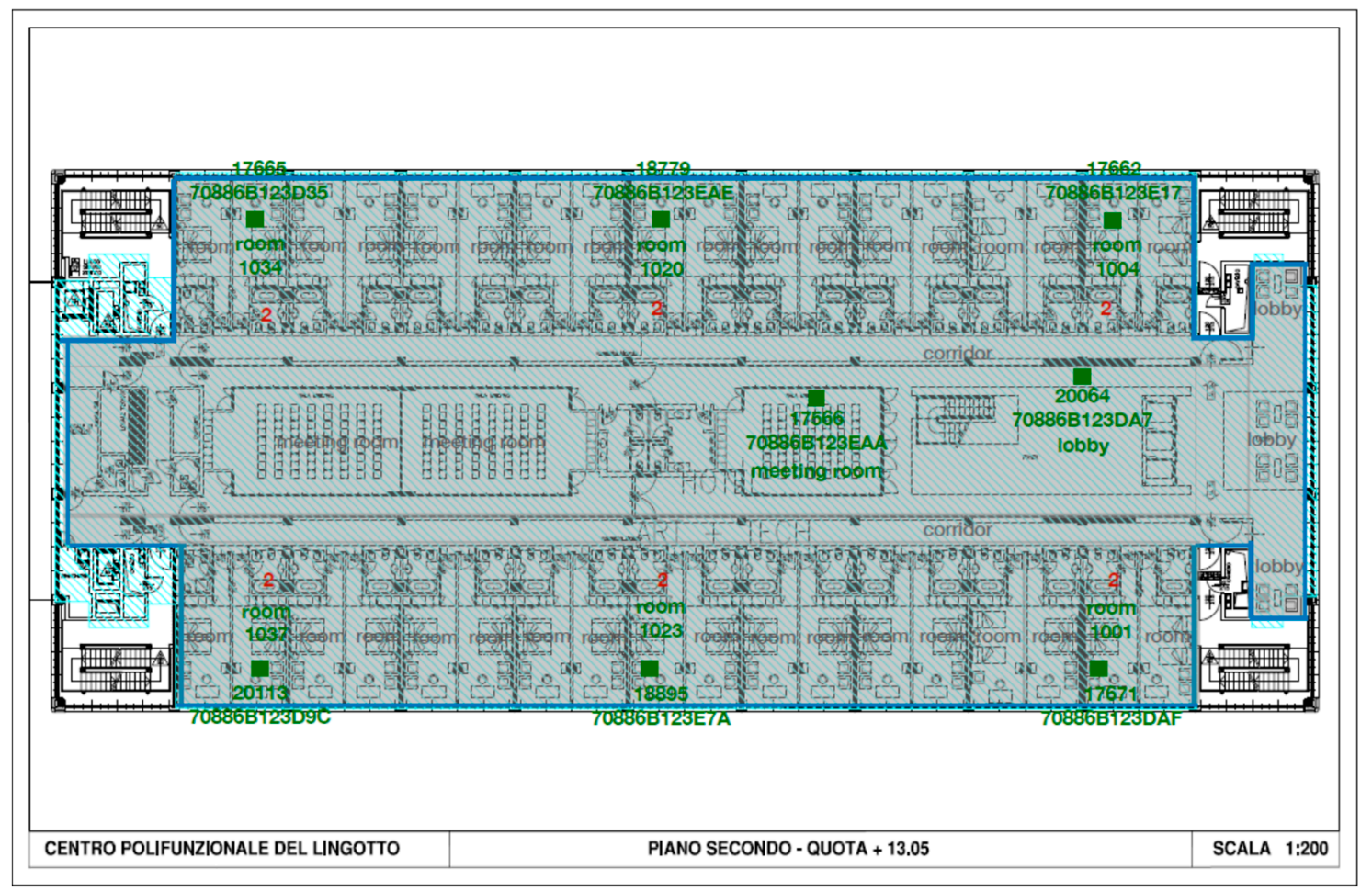

Figure 2. Floorplan of the rooms area, second floor, with indication about the placing of the monitoring platform.

\subsection{Monitoring Techniques and Data Quality}

The monitoring network has been built on company-grade monitoring devices, commercially available and supplied by the partner company (Planetwatch sas-Awair). The devices record data on various airborne pollutants, as well as environmental parameters, and they are compliant with the RESET standard [35]. As no international standard has been set neither in terms of monitoring methods and devices, nor of contaminants of concern at the policy level, RESET standard is the first sensor-based and performance-driven data standard for the general-purpose indoor environments. The RESET standard and certification creates a structure for data quality, continuous monitoring and benchmarking, considering a set of environmental parameters and airborne contaminants. 


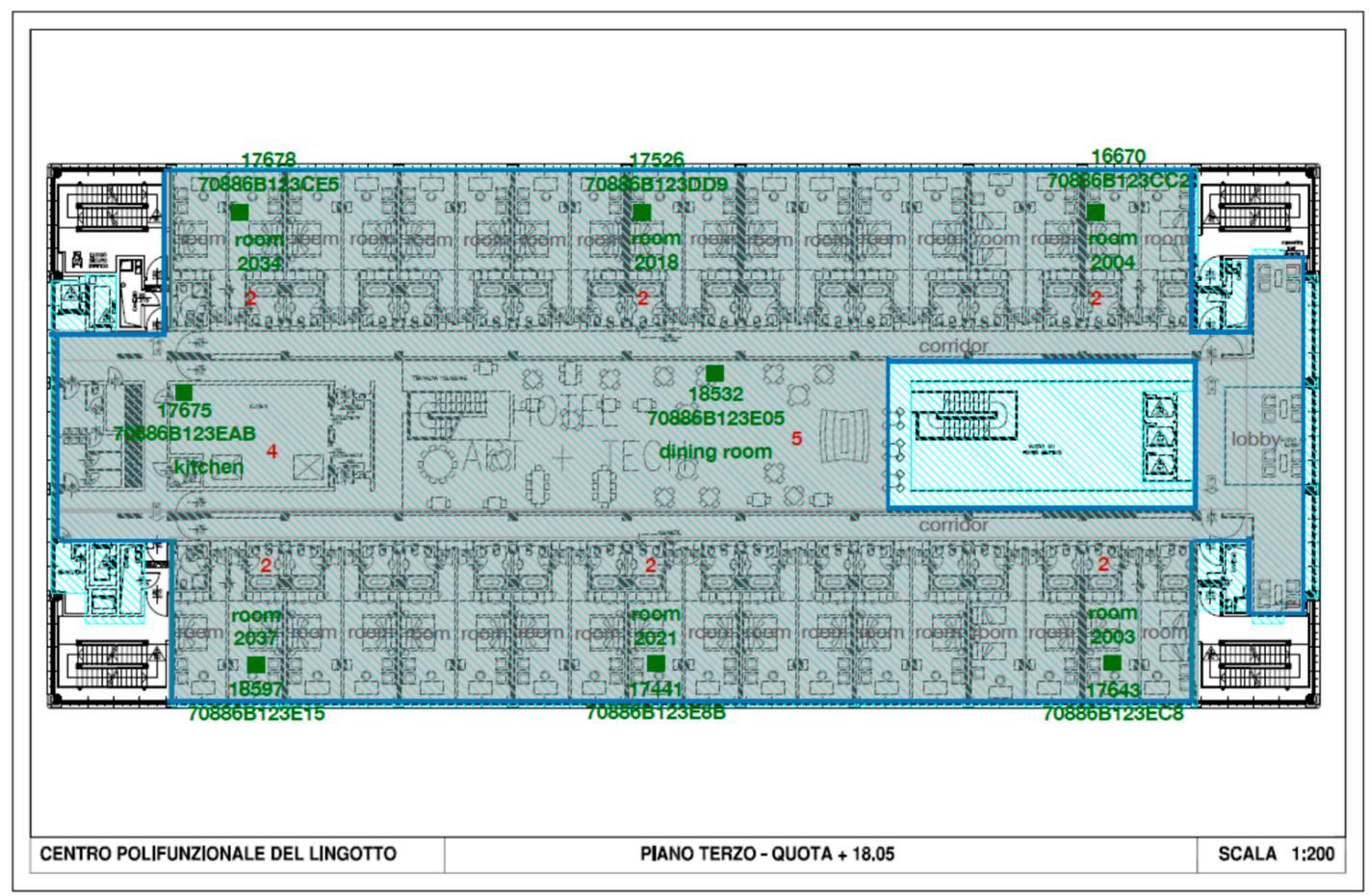

Figure 3. Floorplan of the rooms and restaurant area, third floor, with indication about the placing of the monitoring platform.

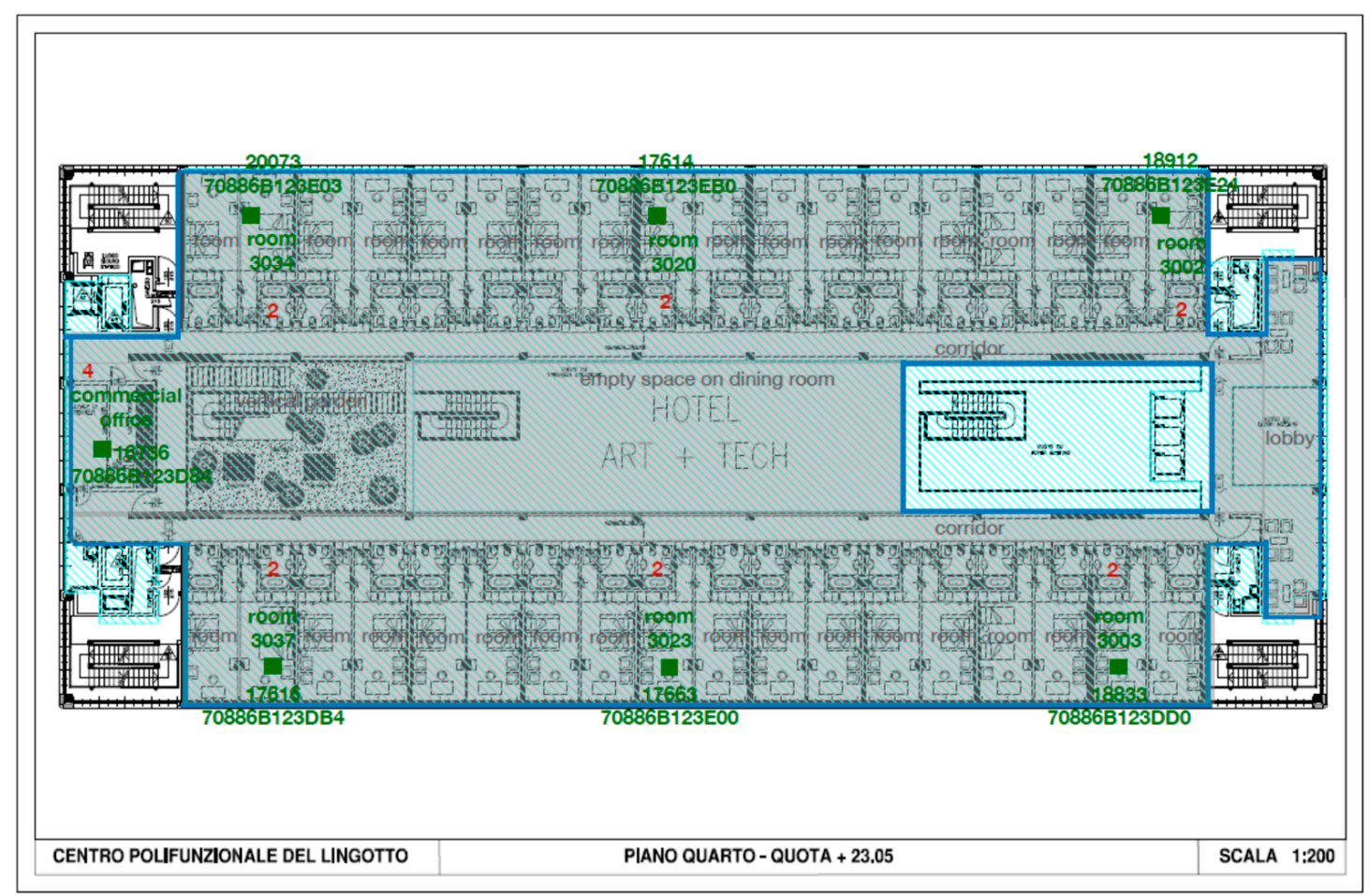

Figure 4. Floorplan of the rooms and restaurant area, fourth floor, with indication about the placing 195 of the monitoring platform. 


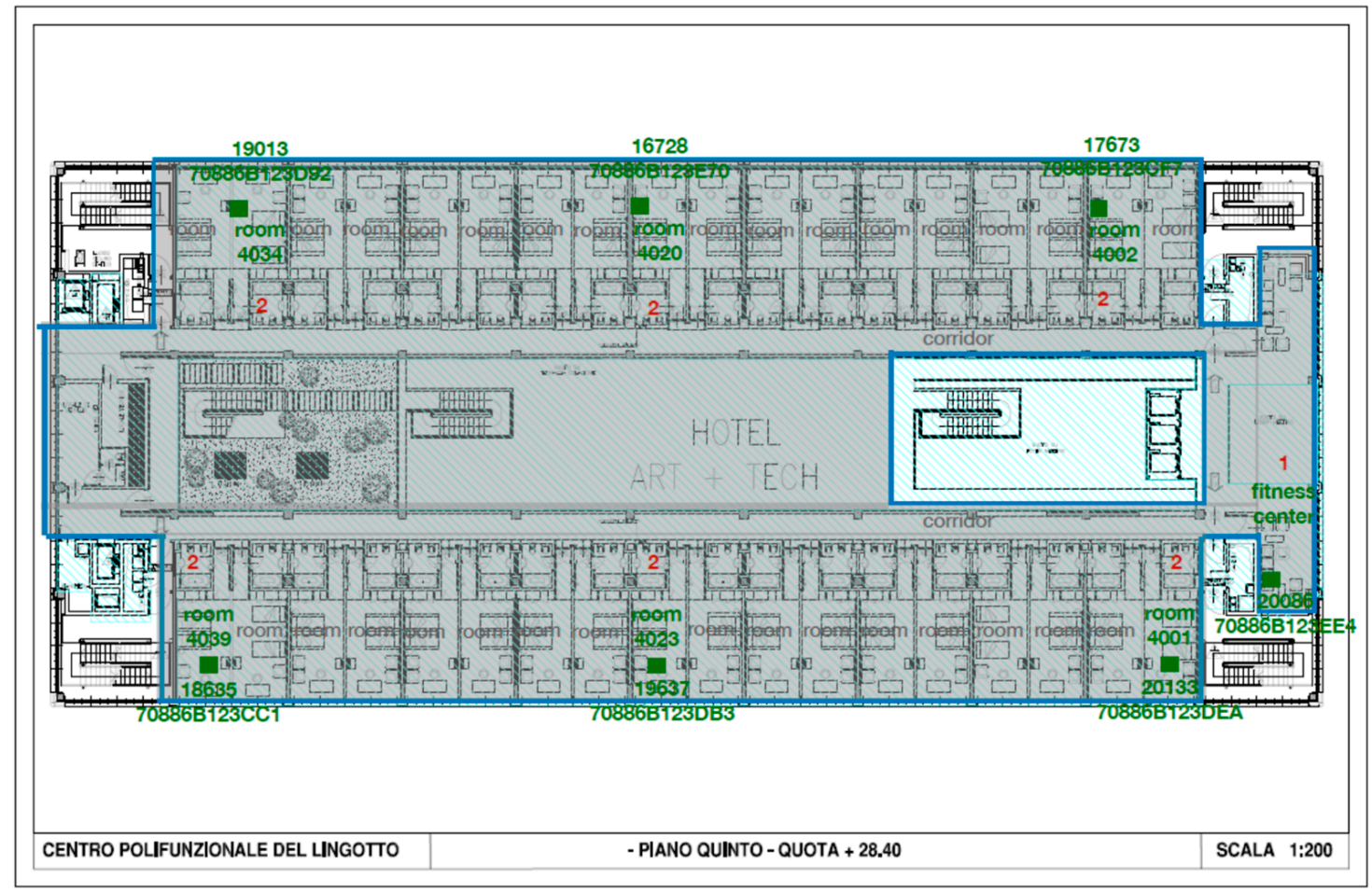

Figure 5. Floorplan of the rooms and fitness center area, fifth floor, with indication about the placing of the monitoring platform.

The pollutants considered in in this study are PM 2.5 (measured in $\mu \mathrm{g} / \mathrm{m}^{3}$ ), VOC (parts per billion-ppb) and $\mathrm{CO}_{2}$ (parts per million-ppm).

PM 2.5 are detected by a laser particle sensor (light scattering), able to measure the air opacity by the projection of an infrared light beam and the detection of photons that are scattered by the impact, with particles passing through the chamber, by a photodiode. This converts the light into a signal which is proportional to particle count and concentration, in a certain size range [32]. The sensor is provided by Honeywell Sensing and the model is HPMA115S0. It is calibrated with the exposure to tobacco cigarette smoke, which correlates with combustion processes and traffic emissions.

VOCs are detected by a Multi-pixel Metal Oxide Semiconductor Sensor (MOS) [36] supplied by Sensirion (SGP30) and calibrated based on ISO 16000-29. The sensing element is basically a capacitor, able to adjust its capacitance on the circuit, thanks to the specific polymer constituting the dielectric [37]. The level of modification into the capacitance is based on the levels of environmental parameters detected, i.e., temperature and humidity, which are determined in this way.

A similar sensor is applied for the determination of the temperature and relative humidity, i.e., a Complementary Metal-Oxide-Semiconductor (CMOS) Sensor, widely appreciated for its high noise immunity and low static power consumption.

A Non-Dispersive Infrared Detector (NDIR) is applied for the detection of carbon dioxide and it is the most common type of sensor used for this purpose on the market. In these sensors, an infrared (IR) lamp directs light close to the $\mathrm{CO}_{2}$ absorption band of 4.26 microns, which works as a marker for $\mathrm{CO}_{2}$ molecules' identification, into a tube filled with air. As the light wave travels along the tube, the $\mathrm{CO}_{2}$ molecules absorb the specific wavelength and, at the end of the tube, the remaining light passes through an optical filter and it is measured by the IR light detector. The measure of $\mathrm{CO}_{2}$ concentration is calculated considering the direct proportion between the light absorbed by $\mathrm{CO}_{2}$ molecules (calculated as the difference between the light emitted by the IR lamp and the light received by the detector) and the number of molecules inside the tube [38]. The equipped sensor 
is T6703, supplied by Telaire/Amphenol, calibrated by Telaire's Patented ABC Logic Self-Calibrated Algorithm.

The devices installed in the hotel acquired data every five minutes. This sampling frequency offers a good compromise between detailed monitoring, allowing to evaluate specific events, such as human activities generating pollution and computational concerns, avoiding overcharging the data acquisition process. With the set sampling frequency, in fact, we are able to detect both quite instant activities, such as perfume diffusion, and more long-term activities, such as the permanence of guests in a room without opening the windows. Over a period of 4 months, our data acquisition has generated only $10 \mathrm{Mb}$ of data, which offers great perspective for the scale-up of the process, with the development of wider networks, ensuring the collection of detailed information.

Each device is equipped with an integrated WiFi communication module for wireless data communication and the connection to the internet cloud, and it is powered by an external wall-mount 220 Vac power supply. The general operating range is between 0 and $40{ }^{\circ} \mathrm{C}$ for temperature and $10-85 \%$ for relative humidity. Details about output resolution, measuring range and accuracy of each sensor are reported in Table 2.

Table 2. Technical details about the sensors implemented by each monitoring platform.

\begin{tabular}{|c|c|c|c|c|}
\hline Sensor & Output Resolution & $\begin{array}{l}\text { Measuring } \\
\text { Range }\end{array}$ & & Accuracy $( \pm \%)$ \\
\hline PM 2.5 & $1(\mu g / m 3)$ & $0-500\left(\mu \mathrm{g} / \mathrm{m}^{3}\right)$ & - & $\begin{array}{l}0-150: \pm 5-15 \% \\
150-500: \pm 5-20 \%\end{array}$ \\
\hline VOCs & $44(\mathrm{ppb})$ & 65-870 (ppb) & - & $\begin{array}{l}62-260: \pm 8.7-15 \% \\
260-870: \pm 8.7-20 \%\end{array}$ \\
\hline $\mathrm{CO}_{2}$ & $5(\mathrm{ppm})$ & 400-5000 (ppm) & . & $\begin{array}{l}\text { 400-2000: } \pm 50-3 \% \\
2000-5000: \pm 50-5 \%\end{array}$ \\
\hline temperature & $0.1\left({ }^{\circ} \mathrm{C}\right)$ & $0-40\left({ }^{\circ} \mathrm{C}\right)$ & & $1\left( \pm^{\circ} \mathrm{C}\right)$ \\
\hline humidity & $1(\% \mathrm{RH})$ & 10-80 (\%RH) & & $8(\%$ RH $)$ \\
\hline
\end{tabular}

\subsection{Data Processing}

We have used the R software to process the data collected. The software allows solid statistical analysis and implements a specific library, "openair", offering relevant tools for air quality data analysis (https:/ / cran.r-project.org/web/packages/openair/index.html, accessed on 2 May 2021).

The data has been divided into sets, based on the type of environment where the device is installed. In particular, we focused on five specific locations in the hotel: rooms, kitchen, fitness center, hall and restaurant. The activities that take place in these environments are representative of the hotel activities in general and they are of particular interest for pollutant detection.

For each environment and for each pollutant, we analyzed the concentration values over the whole period, in terms of evolution of the parameters over time.

The analyses described above have been replicated for each environment monitored. IAQ data deriving from guestrooms have been aggregated to cope with privacy-related concerns.

Finally, outdoor air quality data collected and made publicly available by the Environmental Authority of Piemonte Region, i.e., Arpa Piemonte, have been retrieved (Stazione Torino Lingotto, data retrieved from http:/ / www.regione.piemonte.it/ambiente/aria/ rilev/ariaday/ariaweb-new/, accessed on 2 May 2021). Concentration values and trends registered outdoors were then matched with indoor data collected during the present study, in order to identify possible analogies with the concentration values detected for the contaminants of concern. The ARPA monitoring station in the proximity of the building registers data about different contaminants, such as ammonia, nitrogen dioxide, benzene, black carbon, ozone, etc. (http://webgis.arpa.piemonte.it/qualita_aria_webapp/dati_ anagrafici/index.php?NUMCODICE=001272-806, accessed on 22 April 2021). 


\section{Results}

The following section reports the results obtained during the monitoring period, for the different environments included.

\subsection{General Overview}

A general overview of the results is reported in Table 3, in terms of mean value and standard deviation of each parameter monitored along the whole period of analysis, for all the environments included.

Table 3. Descriptive statistics for the different contaminants monitored, in each environment included.

\begin{tabular}{ccccccc}
\hline \multirow{2}{*}{$\begin{array}{c}\text { Monitored } \\
\text { Environment }\end{array}$} & \multicolumn{2}{c}{ PM 2.5 } & \multicolumn{2}{c}{ VOCs } & \multicolumn{2}{c}{ CO $_{2}$} \\
\cline { 2 - 7 } & Mean & SD & Mean & SD & Mean & SD \\
\hline Hall & 9.33 & 12.57 & 162.41 & 126.42 & 453.31 & 35.68 \\
Rooms & 4.09 & 4.8 & 108.4 & 154.46 & 463.44 & 65.26 \\
Kitchen & 4.3 & 3.83 & 134.48 & 172.44 & 456.62 & 37.23 \\
Restaurant & 4.49 & 4.43 & 143.66 & 90.72 & 452.21 & 37.94 \\
Fitness Center & 4.51 & 3.65 & 154.3 & 267.32 & 459.92 & 40.89 \\
General & 5.34 & 5.86 & 140.65 & 162.27 & 457.1 & 43.4 \\
\hline
\end{tabular}

Considering the mean values, the hall appears to be the area where the contamination in terms of both PM 2.5 and VOCs is higher, while $\mathrm{CO}_{2}$ mean value resulted slightly higher in the rooms. Regarding the standard deviation, testifying to the variability of the concentration values recorded, it resulted higher for the PM 2.5 in the hall, for the VOCs in the fitness center and for $\mathrm{CO}_{2}$ within the rooms. More detailed results are reported in the following sections, aggregated by contaminant.

\subsection{PM 2.5}

Figure 6 reports the concentration of PM 2.5 for the different environments monitored, over the whole period of monitoring. For the rooms, values are calculated as means of the concentrations detected in the fourteen rooms included in the present study. The target values proposed by the RESET standards for PM 2.5, both for regular and high performance, have been included in the figure, as a reference to support the evaluation of the IAQ in absolute terms.

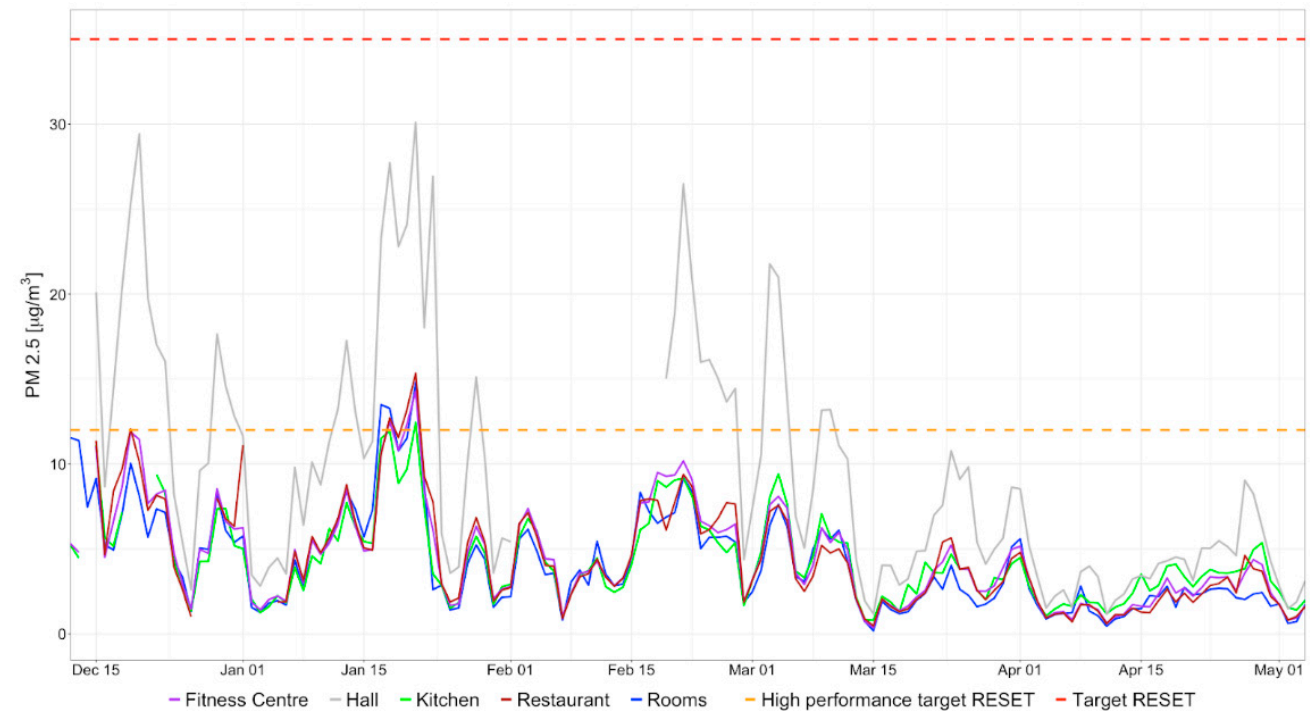

Figure 6. Concentrations of PM $2.5\left(\mu \mathrm{m} / \mathrm{m}^{3}\right)$ detected in the different environments monitored along the whole period of analysis. 
As evident from Figure 6 PM contamination in the class of 2.5 micrometers follows a common pattern, on average, in all the environments monitored, with a remarkable consistency in the whole period, even in absolute values. The hall resulted as the only area where the readings consistently exceeded the other environments', reaching more than $100 \%$ during peak periods, but still in line with the standards proposed by RESET.

In order to set a reference, we retrieved data from Arpa Piemonte and plotted them over time for PM 2.5. Figure 7 reports concentrations detected by Stazione Arpa Torino Lingotto over the same time span of the study. Unfortunately, there are several periods of missing data, offering limited ground for a direct comparison among indoor and outdoor quality data. It is nevertheless evident that the trends appear macroscopically similar, with peaks concentrated in the winter weeks and a decreasing tendency with the proceeding spring season, as expected in outdoor environments due to the evolution of the planetary boundary layer.

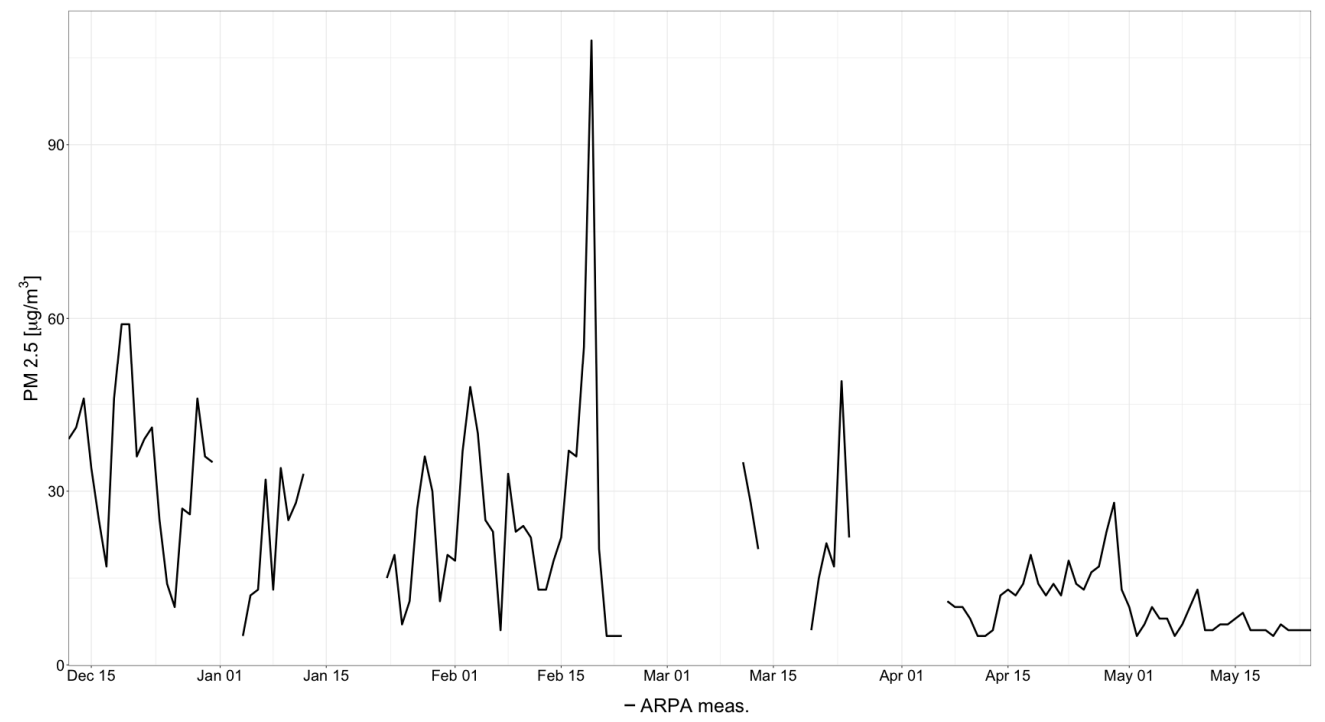

Figure 7. Concentrations of PM $2.5\left(\mu \mathrm{m} / \mathrm{m}^{3}\right)$ detected by Stazione Arpa Torino Lingotto, over the same time span of the study.

\section{3. $\mathrm{VOCs}$}

Figure 8 reports the concentration of VOCs, over the whole period of monitoring for the different environments included. The target values proposed by the RESET standards for VOCs, both for regular and high performance, have been included in the figure, as a reference to support the evaluation of the IAQ in absolute terms.

The average VOCs concentrations registered were lower in the rooms and higher in the hall, which displays the highest mean value, fitness center, which presents the highest standard deviation, and restaurant. The kitchen shows two remarkable peaks, the first during the last weeks of December and the second just before the middle of April.

Repetitive cycles can be identified, with recurrent minimum values over a period of about seven days.

In Table 4, the number of days exceeding the standards proposed by RESET, in terms of mean daily concentrations, are reported. As the number of exceeding days for the rooms is the sum of the twenty-four rooms monitored, it is also reported as the mean value for each room. Results confirm the criticality registered in the fitness center, as days displaying mean VOCs concentrations exceeding the standards represent $24 \%$ of the monitoring period. 


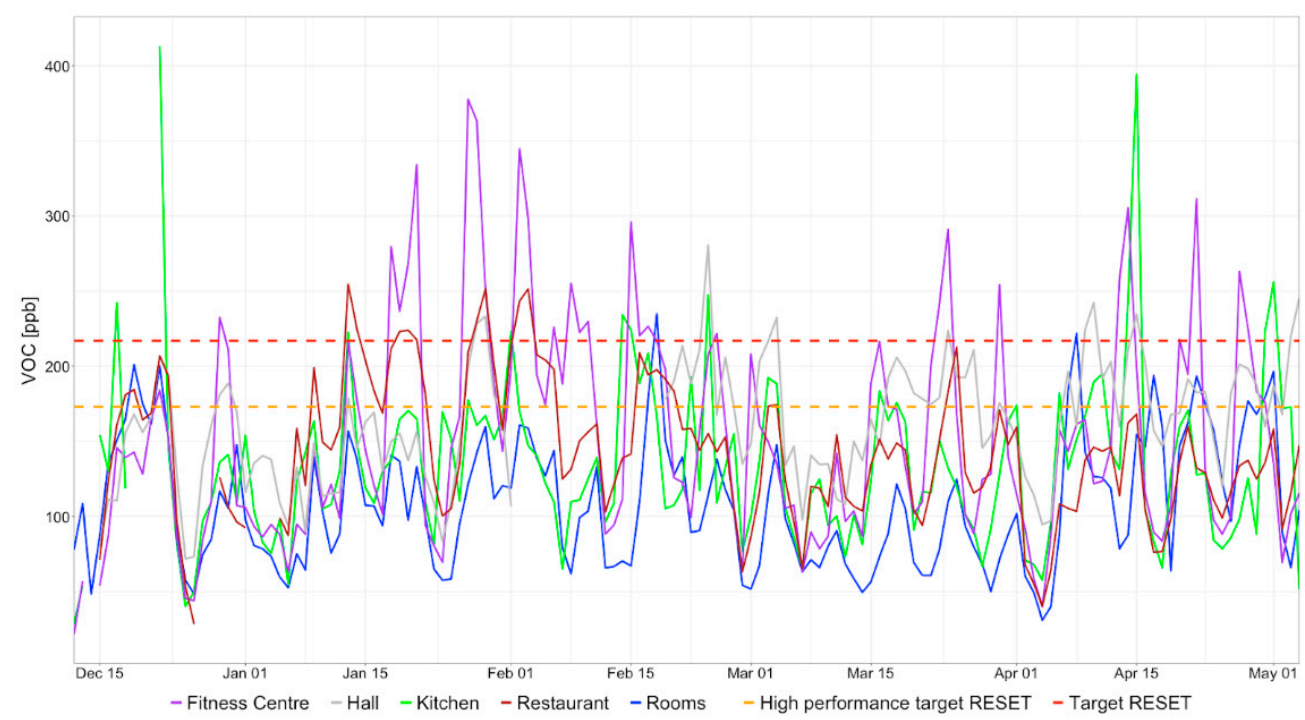

Figure 8. Concentrations of VOCs ( $\mathrm{ppb}$ ) detected in the kitchen across the whole period of analysis.

Table 4. Descriptive statistics for the different contaminants monitored, in each environment included.

\begin{tabular}{cc}
\hline Monitored Environment & VOCs \\
\hline Hall & 10 \\
Rooms & $49(2)$ \\
Kitchen & 11 \\
Restaurant & 9 \\
Fitness Center & 27 \\
General & 106 \\
\hline
\end{tabular}

\section{4. $\mathrm{CO}_{2}$}

Figure 9 reports the concentration of $\mathrm{CO}_{2}$ over the whole period of monitoring for the different environments included in the study. The target values proposed by the RESET standards for $\mathrm{CO}_{2}$, both for regular and high performance, have been included in the figure, as a reference to support the evaluation of the IAQ in absolute terms.

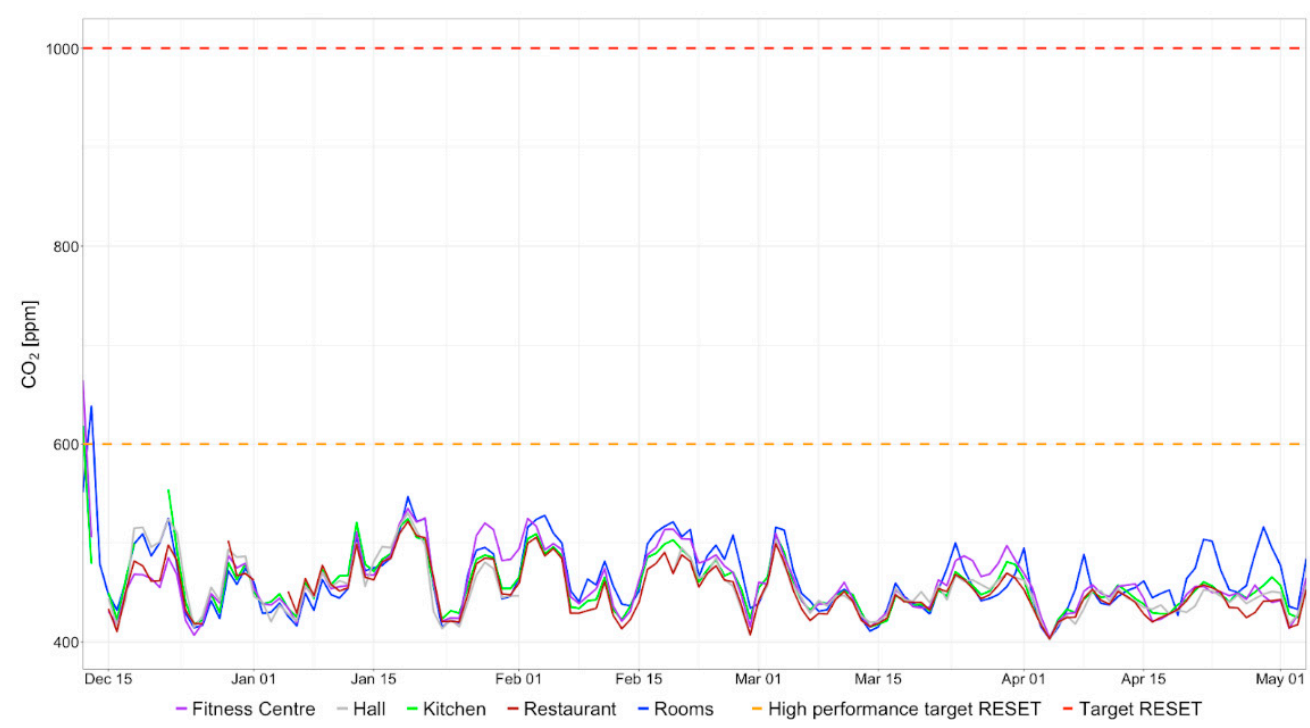

Figure 9. Concentrations of $\mathrm{CO}_{2}(\mathrm{ppm})$ detected in the different environments monitored across the whole period of analysis. 
$\mathrm{CO}_{2}$ concentrations resulted consistently below the target concentrations required by the RESET standards and appear quite aligned across the different environments monitored. Only during the first days of the study did we register $\mathrm{CO}_{2}$ concentrations exceeding the standards proposed, up to levels never replicated afterward. The mean values differed by less than $2.5 \%$ and the standard deviations exceeded the $10 \%$ of the mean only for the rooms.

\section{Discussion and Conclusions}

The COVID-19 crisis has highlighted the relevance of IAQ management, especially in indoor environments, where crowding and people's turnover may give rise to an increased risk of infection related to the exposure to human aerosols. For the hospitality sector, so heavily affected by travel restrictions and containment measures as a response to the pandemic, controls become crucial to design a pathway towards safe reopening and, in that perspective, towards a sustainable management of premises [39]. Following the hierarchical structure of controls aimed at facing the challenges posed by the pandemic (originally proposed by the CDC [40] and revised by Morawska et al. [29]), both administrative and technical actions must enter the management routine of hospitality facilities. As a first response to the surge of the crisis, mainly operational protocols have been implemented, based on standard approaches, such as disinfection of surfaces, limitations for the use of indoor environments and obligation to wear personal protective equipment, but more sophisticated approaches are required in the long term. With our study, we developed a case study in partnership with a major hotel facility, during the pandemic, aimed at implementing a smart IAQ monitoring network into a real-scale context. The study provides a set of contributions to the literature in the field and to practice.

First, we conducted longitudinal data collection over a long period of time, based on a monitoring network fully compliant with the RESET IAQ standards. This represents a major contribution, as, to our knowledge, this is the very first application of RESET standards in the hospitality sector. Moreover, previous studies in the field focused only on spot detection of IAQ and underlined the criticality of prolonging the monitoring period, in order to avoid singularities and support the understanding of local-scale phenomena. In the context of the pandemic and post-pandemic era, the network equipped in the hotel offers the basis for the implementation of a steady monitoring routine, supporting the analysis of the influence of specific activities and occupation of the different areas in the IAQ, in order to provide information to the facility management. For example, from the observation of IAQ data in the period of study, it is possible to detect how the pandemic affected the access to the hotel. Due to travel restrictions related to the pandemic, in fact, the typical customers were limited to business and the average visit schedule excluded the weekends, when we registered the minimum values for all the airborne contaminants monitored, on a regular basis and for all the environments monitored.

Second, IAQ data were collected in environments with different purposes, within the same hospitality premise. Results showed peculiarities of each environment in terms of average values and peak concentrations of the airborne contaminants detected. This allows to outline the contributions of the specific activities performed in the different environments, such as workout and cleaning in the fitness center or cooking in the dining area, giving rise to peaks of concentration on a recurrent basis. The hall, as a unique environment partially open to the outdoors, provides an interesting point for reflection about the possible interdependence with outdoor air quality, as concentration values detected for PM 2.5 differed remarkably from all other environments.

Third, we integrated the monitoring of different contaminants of concern under the same framework. This, combined with the previous elements, allowed to gather several insights, at the general level and more focused on the relationship between the specific contaminants and the environments monitored. Considering the overall performance of the IAQ management system currently in place, it appears generally adequate for the targets proposed by the RESET standards. We can observe how the ventilation system 
is able to promote the exchange of exhaust air, as the levels of $\mathrm{CO}_{2}$ are kept consistently within the targets for all the environments monitored, and PM 2.5 displays a quite similar behavior, except for the concentrations detected in the hall. The hall is typically the area at the interface between the indoor and the outdoor of a hospitality premise, and doors open repeatedly throughout the day. Therefore, the effect of the ventilation system is reduced, and other factors may come into play, such as temporary crowding, e.g., at the check-out time in the morning, or outdoor pollution events. It is worth noticing that PM 2.5 concentrations decrease with time, following a pattern reasonably related to the changing season under two perspectives. First, at the indoor level, where the increasing outdoor temperature typically leads to a decreased heating rate within the building. Second, at the outdoor level, where springtime is generally related with both a decrease in polluting emissions from traffic and households' heating systems and an increase in the planetary boundary layer, leading to reduced PM concentrations in outdoor air.

Considering VOCs management, as general ventilation is less relevant, peculiarities related to the activities performed in the environments emerge as predominant to guide the IAQ. The fitness center, for example, is characterized by recurrent peaks in concentration, exceeding the target values. It is reasonable to relate these peaks with the perspiration from the users of the premise and the consequent extensive cleaning routine implemented during the pandemic. Both of the activities are typically spaced out by long periods when the area is unused, thus justifying the high standard deviation calculated. The restaurant also resulted as an area of concern regarding VOCs concentration, characterized by repetitive peaks, most of the time corresponding to the ones highlighted by the fitness center. This suggests a relation with the rate of occupation of the hotel, as during the toughest periods of the pandemic only restaurants within hospitality premises were allowed to host, and the same was true for fitness centers, and, therefore, all the guests were reasonably forced to perform these activities within the hotel. Guestrooms showed the lowest VOCs concentrations and relatively high $\mathrm{CO}_{2}$, both of which are explained by the fact that most of the rooms remained unoccupied for long periods of time during the pandemic, but for privacy reasons, a more focused analysis was unapplicable. This represents one of the main limitations of the present study and provides grounds for future research, as with the lifting of travel restrictions, more data will become available. The other main limitation is the implementation of low-cost sensing technologies to build the monitoring network, but this has been recognized as an acceptable approach to extend the air monitoring across time and space and improve the availability of data [41].

Based on the results obtained so far, pathways for future research may be outlined, starting from the application of advanced techniques for data analysis, and, in perspective, big data analyses, as the innovative dataset of IAQ data created will be updated continuously. This would allow to detect repetitive patterns of contamination over different time spans automatically, such as days, weeks and years, gathering information about the influence of specific human activities, e.g., cleaning routine, or natural events and phenomena, e.g., effects of the changing seasons or outdoor air quality. In addition to this, the system currently in place could be supplemented with recurring spot monitoring of microbial aerosol performed with standard methodologies, in order to enrich the set of parameters for the IAQ-related risk management.

Author Contributions: Conceptualization and methodology, S.Z. and G.M.; software, D.C.; validation, M.M. and M.L.; investigation, G.M.; data curation, D.C.; writing-original draft preparation, S.Z.; writing-review and editing, M.M. and M.L.; visualization, D.C.; supervision, M.M. and M.L.; project administration, G.M. All authors have read and agreed to the published version of the manuscript.

Funding: This research received no external funding.

Institutional Review Board Statement: Not applicable.

Informed Consent Statement: Not applicable. 
Data Availability Statement: Data are available from the authors, upon request.

Acknowledgments: We would like to acknowledge Giorgio Cavallo, CEO of Lingotto Hotels, and Planetwatch for providing infrastructure for data collection.

Conflicts of Interest: The authors declare no conflict of interest.

\section{References}

1. WHO. Public Health, Environmental and Social Determinants of Health (PHE). 2018. Available online: https://www.who.int/ phe/health_topics/outdoorair/databases/en/ (accessed on 20 May 2021).

2. Ortiz, A.; Guerreiro, C.; Horálek, J. Air Quality in Europe-2019 Report; European Environment Agency: Copenhagen, Denmark, 2019.

3. Nikfar, S.; Malekirad, A.A. Occupational Exposure Limits. In Encyclopedia of Toxicology, 2nd ed.; Wexler, P., Ed.; Academic Press: Cambridge, MA, USA, 2014; pp. 637-640, ISBN 9780123864550.

4. Wallace, L. The Total Exposure Assessment Methodology (TEAM) Study: Summary and Analysis; EPA/600/6-87/002A (NTIS PB88100060); U.S. Environmental Protection Agency: Washington, DC, USA, 1987.

5. Morawska, L.; He, C.; Johnson, G.; Guo, H.; Uhde, E.; Ayoko, G. Ultrafine particles in indoor air of a school: Possible role of secondary organic aerosols. Environ. Sci. Technol. 2009, 43, 9103-9109. [CrossRef] [PubMed]

6. Chang, H.; Capuozzo, B.; Okumus, B.; Cho, M. Why cleaning the invisible in restaurants is important during COVID-19: A case study of indoor air quality of an open-kitchen restaurant. Int. J. Hosp. Manag. 2021, 94, 102854. [CrossRef] [PubMed]

7. Buonanno, G.; Stabile, L.; Morawska, L. Personal exposure to ultrafine particles: The influence of time-activity patterns. Sci. Total Environ. 2014, 468, 903-907. [CrossRef]

8. Lucialli, P.; Marinello, S.; Pollini, E.; Scaringi, M.; Zauli Sajani, S.; Marchesi, S.; Cori, L. Indoor and outdoor concentrations of benzene, toluene, ethylbenzene and xylene in some Italian schools evaluation of areas with different air pollution. Atmos. Poll. Res. 2020, 11, 1998-2010. [CrossRef]

9. EPA. Particulate Matter Basics. 2006. Available online: https://www.epa.gov/pm-pollution/particulate-matter-pm-basics\#PM (accessed on 20 May 2021).

10. Morawska, L.; Ristovski, Z.; Jayaratne, E.R.; Keogh, D.; Ling, X. Ambient nano and ultrafine particles from motor vehicle emissions: Characteristics, ambient processing and implications on human exposure. Atmos. Environ. 2008, 42, 8113-8138. [CrossRef]

11. WHO. Outdoor Air Pollution a Leading Environmental Cause of Cancer Deaths. 2013. Available online: www.euro.who.int/en/ health-topics/environment-and-health/air-quality/news/news/2013/10/outdoor-air-pollution-a-leading-environmentalcause-of-cancer-deaths (accessed on 11 May 2021).

12. Long, C.M.; Suh, H.H.; Koutrakis, P. Characterization of indoor particle sources using continuous mass and size monitors. J. Air Waste Manag. Assoc. 2000, 50, 1236-1250. [CrossRef]

13. Ramos, C.A.; Wolterbeek, H.T.; Almeida, S.M. Exposure to indoor air pollutants during physical activity in fitness centers. Build. Environ. 2014, 82, 349-360. [CrossRef]

14. Corsi, R.L.; Siegel, J.A.; Chiang, C. Particle resuspension during the use of vacuum cleaners on residential carpet. J. Occup. Environ. Hyg. 2008, 5, 232-238. [CrossRef] [PubMed]

15. Bourdrel, T.; Annesi-Maesano, I.; Barrak, A.; Maesano, C.N.; Bind, M.-A. The impact of outdoor air pollution on COVID-19: A review of evidence from in vitro, animal, and human studies. Eur. Res. Rev. 2021, 30, 200242. [CrossRef] [PubMed]

16. Conticini, E.; Frediani, B.; Caro, D. Can atmospheric pollution be considered a co-factor in extremely high level of SARS-CoV-2 lethality in Northern Italy? Environ. Pollut. 2020, 261, 114465. [CrossRef] [PubMed]

17. Kumar, P.; Morawska, L. Could fighting airborne transmission be the next line of defence against COVID-19 spread? City Environ. Interact. 2019, 4, 100033. [CrossRef]

18. Setti, L.; Passarini, F.; De Gennaro, G. Potential role of particulate matter in the spreading of COVID-19 in Northern Italy: First observational study based on initial epidemic diffusion. BMJ Open 2020, 10, e039338. [CrossRef]

19. Santarpia, J.L.; Rivera, D.N.; Herrera, V.; Morwitzer, M.J.; Creager, H.M.; Santarpia, G.W.; Crown, K.K.; Brett-Major, D.M.; Schnaubelt, E.R.; Broadhurst, M.J.; et al. Transmission potential of SARS-CoV- 2 in viral shedding observed at the University of Nebraska medical center. medRxiv 2020. [CrossRef]

20. Liu, Y.; Ning, Z.; Chen, Y.; Ming, G.; Yingle, L.; Kumar, G.N.; Sun, L.; Duan, Y.; Cai, J.; Westerdahl, D.; et al. Aerodynamic characteristics and RNA concentration of SARS-CoV-2 aerosol in Wuhan hospitals during COVID-19 outbreak. bioRxiv 2020, 982637. [CrossRef]

21. Wu, X.; Braun, D.; Schwartz, J.; Kioumourtzoglou, M.A.; Dominici, F. Evaluating the impact of long-term exposure to fine particulate matter on mortality among the elderly. Sci. Adv. 2020, 6, eaba5692. [CrossRef]

22. Zhao, Y.; Richardson, B.; Takle, E.; Chai, L.; Schmitt, D.; Xin, H. Airborne transmission may have played a role in the spread of 2015 highly pathogenic avian influenza outbreaks in the United States. Sci. Rep. 2019, 9, 11755. [CrossRef]

23. Ma, Y.; Zhou, J.; Yang, S.; Zhao, Y.; Zheng, X. Assessment for the impact of dust events on measles incidence in Western China. Atmos. Environ. 2017, 157, 1-9. [CrossRef] 
24. Chen, G.; Zhang, W.; Li, S.; Williams, G.; Liu, C.; Morgan, G.G.; Jaakkola, J.J.K.; Guo, Y. Is short-term exposure to ambient fine particles associated with measles incidence in China? A multi-city study. Environ. Res. 2017, 156, 306-311. [CrossRef]

25. OECD. Rebuilding Tourism for the Future: COVID-19 Policy Responses and Recovery; Organisation for Economic Co-Operation and Development: Paris, France, 2020.

26. Barkas, P.; Honeck, D.; Rubio, E. International Trade in Travel and Tourism Services: Economic Impact and Policy Responses during the COVID-19 Crisis; WTO Working Paper; WTO: Geneva, Switzerland, 26 August 2020.

27. UNWTO. Impact Assessment of the Covid-19 Outbreak on International Tourism. 2020. Available online: https://www.unwto. org/impact-assessment-of-the-covid-19-outbreak-on-international-tourism (accessed on 11 May 2021).

28. Sharma, G.D.; Thomas, A.; Paul, J. Reviving Tourism post-COVID-19: A resilience based framework. Tour. Manag. Persp. 2021, 37,100786 .

29. Morawska, L.; Tang, J.W.; Bahnfleth, W.; Bluyssen, P.M.; Boerstra, A.; Buonanno, G.; Cao, J.; Dancer, S.; Floto, A.; Franchimon, F.; et al. How can airborne transmission of COVID-19 indoors be minimised? Environ. Int. 2020, 142, 105832. [CrossRef] [PubMed]

30. Villeneuve, H.; O'Brien, W. Listen to the guests: Text-mining Airbnb reviews to explore indoor environmental quality. Build. Environ. 2020, 169, 106555. [CrossRef]

31. Chang, H.; Huh, C.; Legendre, T.S.; Simpson, J.J. Exploring particulate matter pollution in hotel guestrooms. Int. J. Cont. Hosp. Manag. 2020, 32, 1131-1162.

32. Zanni, S.; Lalli, F.; Foschi, E.; Bonoli, A.; Mantecchini, L. Indoor Air Quality Real-Time Monitoring in Airport Terminal Areas: An Opportunity for Sustainable Management of Micro-Climatic Parameters. Sensors 2018, 18, 3798. [CrossRef]

33. Asadi Costa, J.J.; Gameiro da Silva, M. Indoor air quality audit implementation in a hotel building in Portugal. Build. Environ. 2011, 46, 1617-1623. [CrossRef]

34. Chan, W.; Lee, S.-C.; Hon, A.; Liu, L.; Li, D.; Zhu, N. Management learning from air purifier tests in hotels: Experiment and action research. Int. J. Hosp. Manag. 2015, 44, 70-76. [CrossRef] [PubMed]

35. RESET. RESET Air Standards. 2018. Available online: https://www.reset.build/standard/air (accessed on 11 May 2021).

36. Rüffer, D.; Hoehne, F.; Bühler, J. New Digital Metal-Oxide (MOx) Sensor Platform. Sensors 2018, 18, 1052. [CrossRef]

37. Baker, R.J. CMOS: Circuit Design, Layout, and Simulation, 2nd ed.; Wiley-IEEE: Piscataway, NJ, USA, 2008; p. xxix, ISBN 978-0-470-22941-5.

38. Vincent, T.; Gardner, J.W. A low cost MEMS based NDIR system for the monitoring of carbon dioxide in breath analysis at ppm levels. Sens. Act. B Chem. 2016, 236, 954-964. [CrossRef]

39. Jones, P.; Comfort, D. The COVID-19 crisis and the sustainability in the hospitality industry. Int. J. Hosp. Manag. 2020, 23, 3037-3050. [CrossRef]

40. CDC. Hierarchy of Controls; Centers for Disease Control and Prevention: Atlanta, GA, USA, 2015.

41. Morawska, L.; Thai, P.K.; Liu, X.; Asumadu-Sakyi, A.; Ayoko, G.; Bartonova, A.; Bedini, A.; Chai, F.; Christensen, B.; Dunbabin, M.; et al. Applications of low-cost sensing technologies for air quality monitoring and exposure assessment: How far have they gone? Environ. Int. 2018, 116, 286-299. [CrossRef] 